\title{
SIMULATION AND PERFORMANCE ANALYSIS OF ROUTING PROTOCOLS FSR AND ZRP IN VEHICULAR AD-HOC NETWORK (VANET)
}

\author{
Putri Annisa Septianti \\ School Of Electrical Engineering Telkom University Bandung, Indonesia \\ pannisaseptianti@gmail.com \\ Rendy Munandi \\ School Of Electrical Enginnering Telkom University Bandung, Indonesia \\ Rendymunandi@telkomuniversity.ac.id \\ Ridha Muldina Negara \\ School Of Electrical Engineering Telkom University Bandung, Indonesia \\ ridhanegara@gmail.com
}

\begin{abstract}
Vehicular Ad-Hoc Network (VANET) is a wireless routing network which used ad hoc network system as the basis. VANET was formed to give solution to the unclear network infrastructure or frequently changing network topology. The change of speed and the nodes amount in an area influenced the overhead level in sending message and end to end delay with low packet loss. The right routing protocol selection has an important role in guarantee the Quality of Service in VANET which needs low delay and overhead. This study analyzed the Fisheye State Routing (FSR) protocol performance as a proactive routing protocol that renew the table routing in certain period and Zone Routing Protocol (ZRP) as a hybrid protocol that uses zone and hop distant to decide the table routing renewal in sending data with Cisco codec G 711 standard in highway areas using NS-2.31 and NS-2.35 and traffic simulator SUMO 0.12.3. Moreover, the measured metrics performances were Average end-to-end delay, Normalized Routing Load, Average Throughput, Packet Delivery Ratio (PDR), and Routing Overhead.
\end{abstract}

\section{Keywords: VANET, NS-2, FSR, ZRP, SUMO}

\section{Introduction}

VANET was formed to give solution to the unclear network infrastructure or frequently changing network topology. The frequent problem found in designing VANET was when the speed in every vehicle and the number of vehicles increased so the change of topology is even faster causing communication disturbance in the network. In this era, the common problem found in VANET was the signal loss [7, 10] caused by many reasons. According [2] routing protocol VANET should face the challenges such as topology changes, high mobility, fault tolerance, real-time transmission, flexibility and scalability.

As for that condition, there is an algorithm that suit the VANET [2] algorithm routing criteria namely FSR and ZRP. The prior study done by SumayaThaseen [9] explained about routing protocol FSR and ZRP quality in MANET. VANET is a derivation from Mobile Ad-Hoc Network (MANET). The basic difference between MANET and VANET was the number of users participated in the network (node) in VANET changes quickly and unpredictable. This point made VANET known as dynamic topology so the right routing protocol needed for nodes to communicate.

Protocol routing in accordance to topology is one of a category of routing protocol in VANET and more efficient, since the nodes in this network movefreely and quick along the track assigned. This study analyzed the comparison of FSR and ZRP performance to get better performance in assigning VANET routes. ZRP is one of hybrid routing protocol, based on two protocols known as IntrAzone Routing Protocol (IARP) and Interzone Routing Protocol (IERP). Through IARP, every node identified the distant (minimal) to all nodes in its routing nodes. Eventhough the network was wide, the update process distributed locally only in its routing zone, not to the whole network. IERP responsible to find routes to nodes located outside the zone. In the study [1] known that ZRP had high overhead value. This reason made the writer interested to seek for other routing algorithm that has low overhead value. Fisheye State Routing (FSR) was implicit routing protocol, thought as proactive protocol and link state routing protocol based that adapted to wireless ad hoc. Relay in link state protocol assigned as the base and had the ability to give information directly to the routing by maintaining the topology map in every node. By doing so, it could maintain the newest information from the nodes through link state table. In every node network, full topology map being saved then used. In the study [5], the result shown that FSR was one of routing algorithm with low overhead value.

\section{Routing Protocols}

In this study, topology based routing protocol was used. This protocol used information about available network topology and communication link between nodes to routing decision. FSR and ZRP were routing protocols used.

\section{A. Proactive Routing Protocol, FSR}

Fisheye State Routing (FSR) was based on proactive routing. The characteristics of "fisheye" were the information in the focus length could be received clearly, while the ones outside the focus length were unclear. FSR routing protocol made use of fisheye features to relay routing that renew information with different frequency so it decreased the routing overhead. FSR routing protocol distributed information using "Fisheye" technology, and did not relay routing update information to the whole network so the overhead decreased caused by information renewal, while 
linkstate routing protocol would renew information to the whole network when there was a change in the nodes. FSR was a development of GSR. GSR used large amount of bandwidth as a measurement of huge message updates.

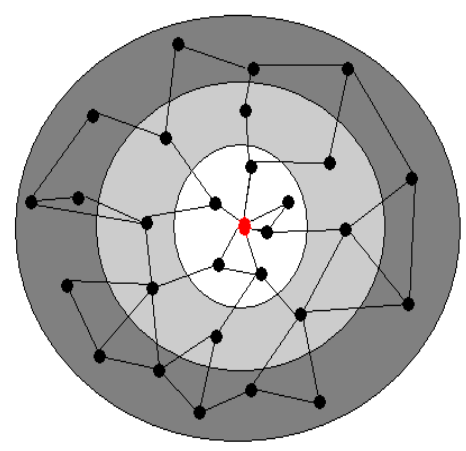

Fisheye State Routing (FSR) was a derivation from GSR. GSR had big packet measurement because it updated every information related to nodes, causing it spent a lot of bandwidth. In FSR, every update messages was not contain the whole information about nodes. On the other hand, the closer nodes information exchanges were more often than the faraway nodes so it decreased the message updates measurement. So, every node got accurate information of their neighborhood, information details and accuracy decrease as the distance increased. Figure 1 defined the fisheye scope for the center node (red). Scope defined as the reachable nodes in some hops. The center of node had the most accurate information about the nodes inside the white circle. Although node had inaccurate information about the distant neighborhood, the packet directed correctly because the route information was more accurate as the packet moved closer to the destination. FSR was a good scale for a huge network, overhead cost handled in this scheme.

\section{B. Hybrid Protocol, ZRP}

ZRP is one of Topology Based Routing Protocols that made and developed to face the challenge in city streets which has buildings, trees, rails, and traffic signs which potentially obstruct the data transfer between vehicles. ZRP had a zone in every node and used few routing protocol techniques neither in nor between zones of every node, depends on its own advantages and disadvantages as the uniqueness. Proactive routing used when in the zone of nodes, while reactive routing used between zones of nodes.

In ZRP there were two route searching methods; (1) Intrazone Routing Protocol (IARP), and (2) Interzone Routing Protocol (IERP). In ZRP, it works according to zone concept. In this zone there was a term called "radius" that the distance shown as hops. Figure 2 is the example of ZRP Routing with 2 hops radius. In the figure, two hops radius shown with a big circle. Nodes in ZRP divided into two parts namely peripheral nodes and interior nodes. Peripheral nodes are the nodes that have at least the same distant with the assigned radius from the node source. The nodes which have less distant than the radius assigned from the node source known as interior nodes.

\section{Intrazone Routing Protocol (IARP)}

In ZRP, every node did the checking to the destined node proactively. Every node had its own zone that assigned by hops. Every node saved information about routes in its own zone. Route request in IARP was more efficient because there was a multicast process called bordercasting. Bordercasting did direct query request to every node located at the outer border of every zone if the destined zone was unavailable. The nodes which located in the border of each zone known as peripheral node, while nodes located inside the zone called interior node.

Figure 2: Example of IARP and peripheral node ${ }^{[4]}$

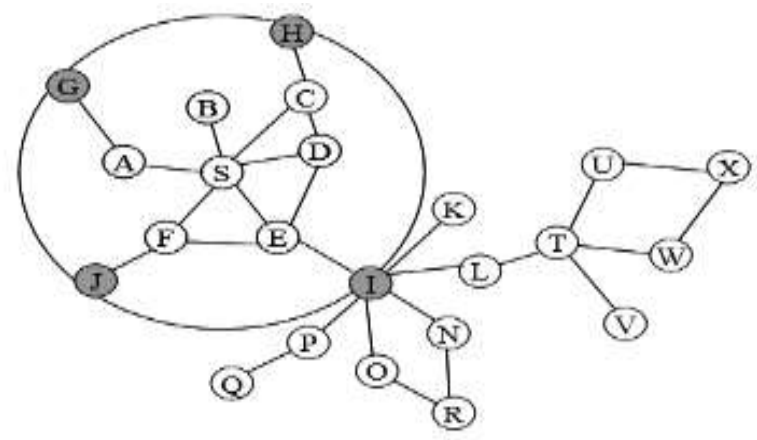


Node $S$ had a packet to send to node $X$, radius zone $r=2$. Node used the table routing given by IARP to check whether the destination is inside the zone. Because it was not found, the route request released using IERP. The request was a bordercast to the peripheral nodes. Each of it seeks for its own table routing for destination nodes.

\section{Interzone Routing Protocol (IERP)}

IERP in ZRP was done to found the destination of nodes located outside the zone of node source. IERP used bordercasting to connect the peripheral nodes to nodes located outside the zone. For the data transfer procedures, the nodes would find out whether its destination located in node source radius or not; if yes, then the path to reach that node would be assigned, and if not, the node source would send bordercast in the form of route request to peripheral node source, then the process would be re-do. If the destination found then the route reply would be sent to the node source indicated that the destination had already found then the path would be formed. The process remained until all the packet received in the destination.

\section{VANET Application}

According to its functions, VANET classified into three main classes namely safety oriented, convenience oriented, and commercial oriented [6]. Safety and convenience application would give information related to roads condition, vehicles, accident warning, and traffic management. Commercial application, on the other hand, would give drivers entertainment and supporting services such as internet access, streaming, and etc.

Table 1: VANET Applications ${ }^{[6]}$

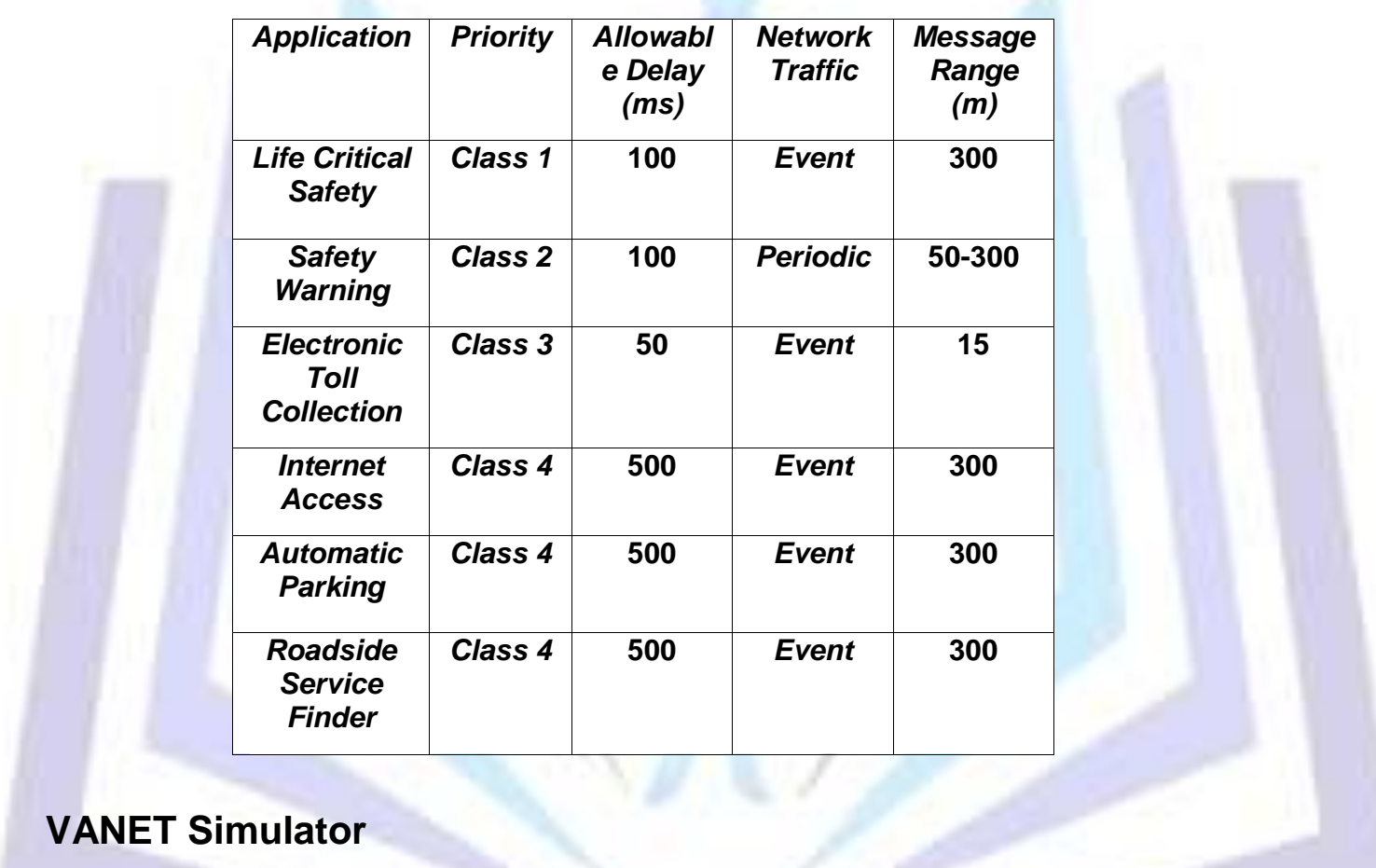

There are three kinds of simulation tools needed to operate the VANET simulation, they are Network Simulator (operates the simulation and gives output parameter), Mobility Simulator (generates the nodes movement), and Integrated Simulator (integrates mobility simulator and network simulator).

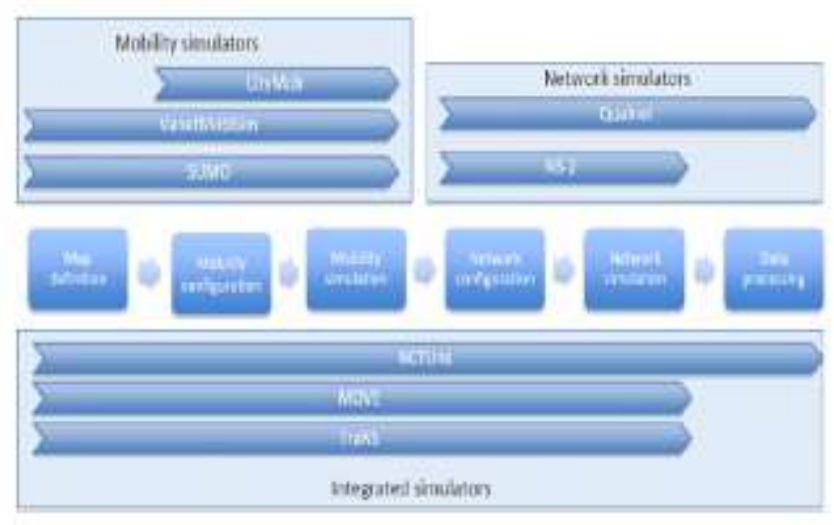

Fugure 3: VANET Simulator ${ }^{[3]}$ 


\section{MODELING SYSTEM}

\section{A. Network Design}

In this study, Ad hoc network architecture used where the node was the vehicle and there was no infrastructure. In accordance to ad hoc network characteristic, this network did not need backbone infrastructure or independent.

The network design in this study used node to illustrate vehicles. To communicate, vehicles connected directly to others without the road side infrastructure. The speed tested taken from the constitution no. 22 year 2009 clause 287 verse 5 about vehicle speed limit which in the city is $50 \mathrm{~km} / \mathrm{hr}$, in habitation (crowds) $25 \mathrm{~km} / \mathrm{hr}$, and highway maximum $100 \mathrm{~km} / \mathrm{hr}$. Because of that, the speed tested in this final project scenario was around $80 \mathrm{~km} / \mathrm{hr}-100 \mathrm{~km} / \mathrm{hr}$.

\section{B. Node Movement Model}

The movement of nodes or mobility model used random way point so the nodes movement were very random, depends on the road conditions. The amount of nodes used was around 80 to 220 due to the data available. The speed also followed the data from the Indonesian police. The selection of this model is to be as similar as the reality where the movements in the streets were very random so, hopefully it could model the real condition.

In this final project, the test was done in highway area scenario for 180 seconds. Then there were some tests to see the factors that could influence the VANET performance and the compared routing protocols. Nodes amount and speed were later known as the factors which influence the performance. The amount of nodes tested in the highway area was 80 to 220. The data type used was User Datagram Protocol (UDP), and used Constant Bit Rate (CBR) in background traffic. The packet size was 640 byte. CBR sent data every 0.05 seconds and the rate was $64 \mathrm{kbps}$ as the standard of Cisco codec G 711 .

Table 2: Simulation Parameter

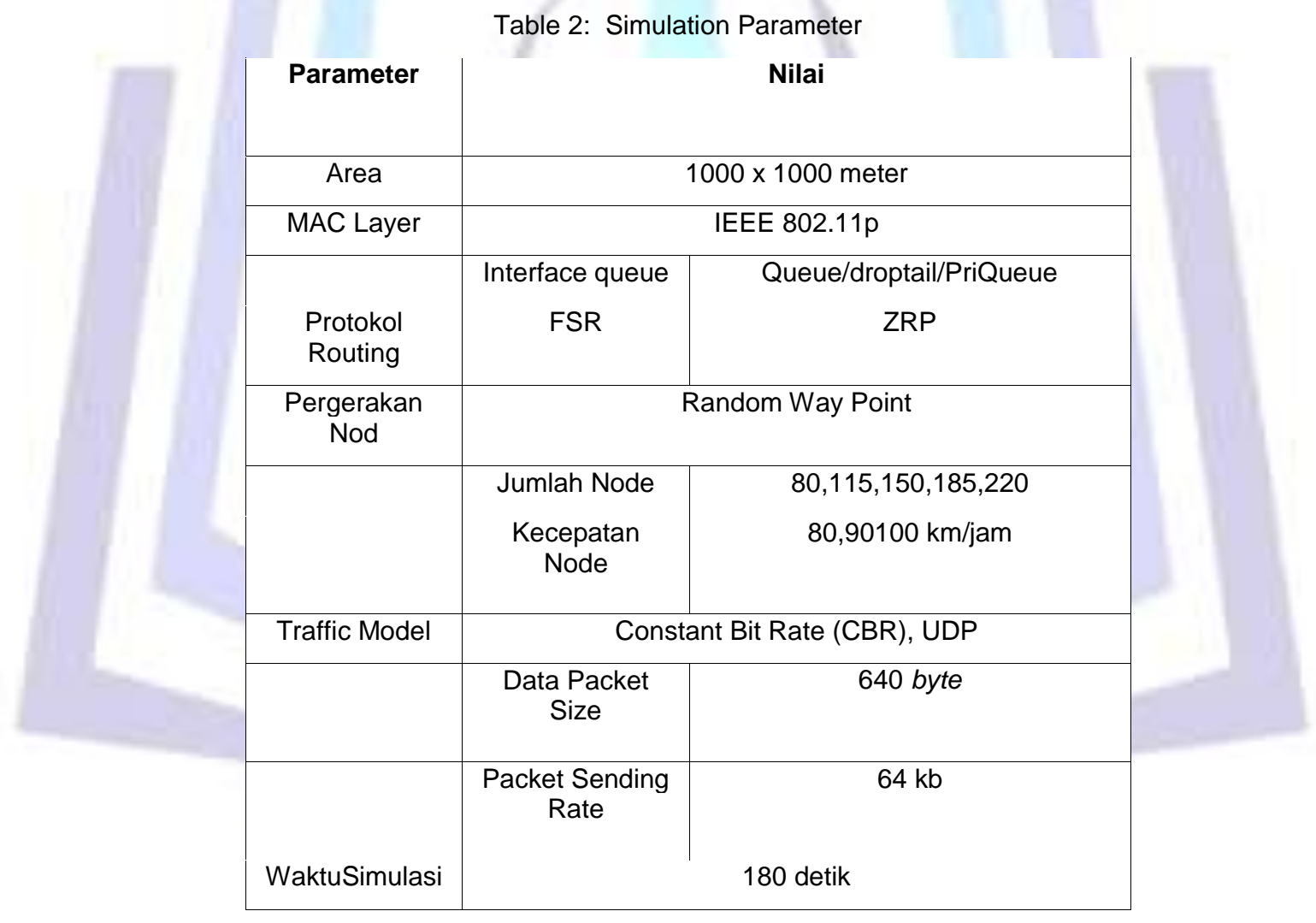

\section{SIMULATION AND ANALYSIS}

After $10 \%$ nodes in the simulation used in VANET network by using FSR and ZRP algorithm routing protocols, the file tracing that had extension.tr was available. The data gave information about packet transfers that could be analyzed by the file which had extension.awk that able to process the information to be the data needed to compare the performances of those two routing protocols. The data parameter results used to see the average of throughput, average end to end delay, routing overhead, NRL, and packet delivery ratio from both routing protocols performances. Those parameters have already been explained in the literature review and system design. The results of the data were shown in graphics.

\section{Node Speed Changes Scenario}

\section{a. Packet Delivery Ratio and Throughput Measurement}

6799 | $\mathrm{P}$ a g e

April, 2016
Council for Innovative Research w w w. cirworld.com 


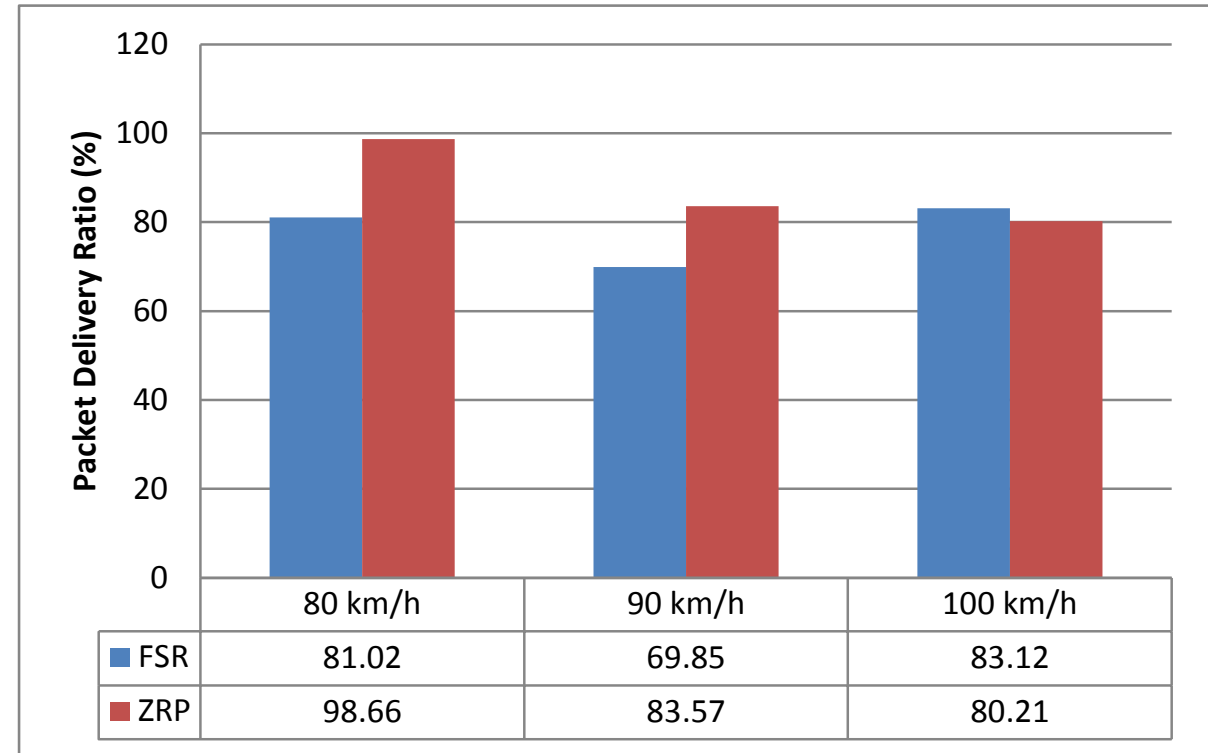

Figure 5: The effects of node speed for PDR

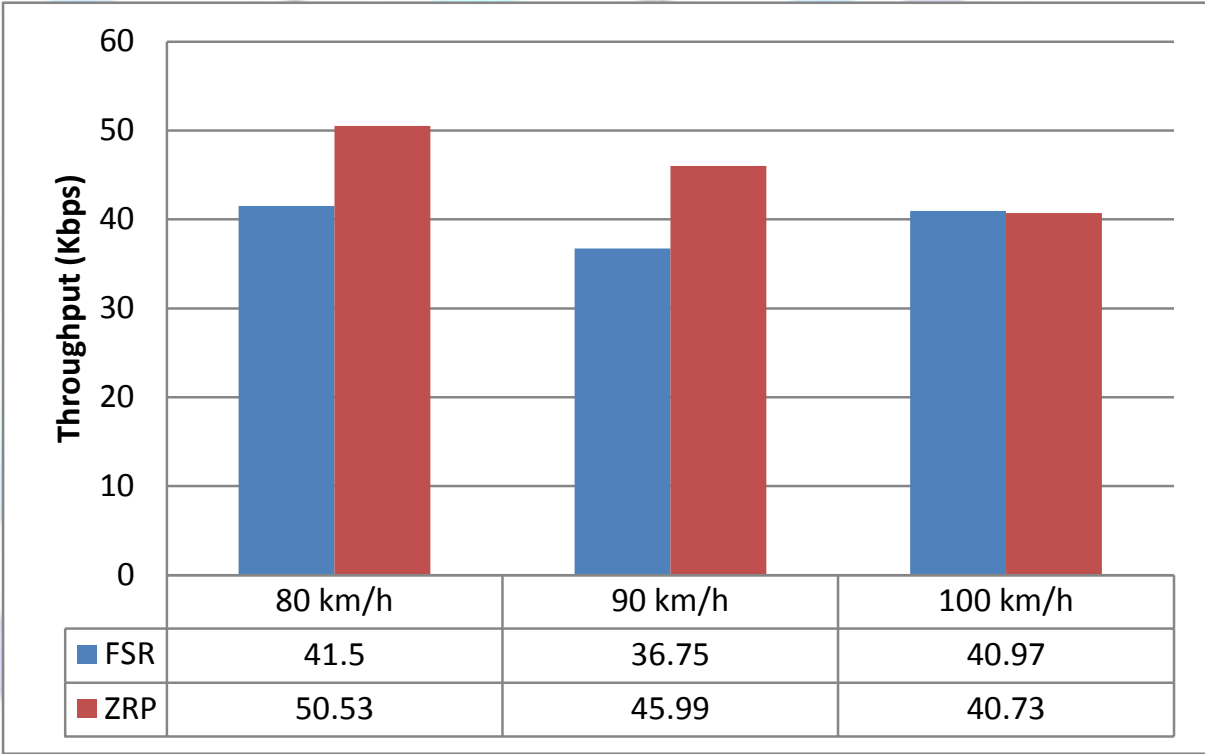

Figure 6: The effects of speed towards throughput

In measuring the performance of a routing protocol in packet data transfer, PDR influenced by throughput value. PDR performance gave an illustration about how well a protocol sends packet data in the varied speed that could be measured by the successful percentage, while throughput measured by a unit of measure per time.

The graphic trend decreased when the node speed increased, PDR in ZRP had more value, in $80 \mathrm{~km} / \mathrm{hr}$, reached $98.66 \%$ and in maximum speed of $100 \mathrm{~km} / \mathrm{hr}, 80.21 \%$ and attained $50.53 \mathrm{kbps}$ throughput value in the speed of $80 \mathrm{~km} / \mathrm{jam}$ and $40.73 \mathrm{kbps}$ in $100 \mathrm{~km} / \mathrm{hr}$ speed. In FSR, the value of PDR and RO in the speed of $80 \mathrm{~km} / \mathrm{hr}$ and $100 \mathrm{~km} / \mathrm{hr}$ were $81.02 \%$ and $83.12 \% ; 41.5 \mathrm{Kbps}$ and $40.97 \mathrm{Kbps}$ consecutively.

There was a fluctuation in the graphic, when the speed was $100 \mathrm{~km} / \mathrm{hr}$, the PDR value and FSR throughput increased from the speed of $90 \mathrm{~km} / \mathrm{hr}$ which were $69.85 \%$ to $83.12 \%$ and the former throughput value was $36.75 \mathrm{Kbps}$ became $40.97 \mathrm{Kbps}$. It can be called as an anomaly that happened in the simulation scenario. Theoretically, the faster nodes speed would decrease the PDR value because the distant among nodes were further. It was because its own nodes, the faster the nodes could cause the distant became further so it made the changes of network topology and resulted in re-searched the routes then decreased the PDR ratio and throughput.

The increase of PDR and throughput in FSR could happen because the working process of the routing algorithm. Every update messages was not contain the information of every node. In contrast, the information exchanges about nearer nodes happened more often than the distant nodes so it decreased the size of the messages. So, every node got accurate and detail information about their neighbor and the accuracy and details would decrease when the distant 
increased. Even though the node had no accurate information about the distant node, the packet directed correctly because the route information became more accurate since the packet move closer to the destination so the routing protocols were good in assigning or seeking for the route.

There were some factors that influence the throughput value, one of them was link endurance that formed from the track searching. In figure 6 , it can be seen that the throughput value of both routing protocols algorithm were not really different in this scenario. Both of them tend to decreased as the node speeds increased though they were not very significant, this thing showed the effect of nodes movement. The faster the speed of nodes, the probability of link failure increased too, and the throughput value would be decreased. Throughput tends to be stable in the highway area where the road condition was swift and the speed was constant so the probability of topology changes was minimal.

\section{b. Routing Overhead and Normalized Routing Load Measurement}

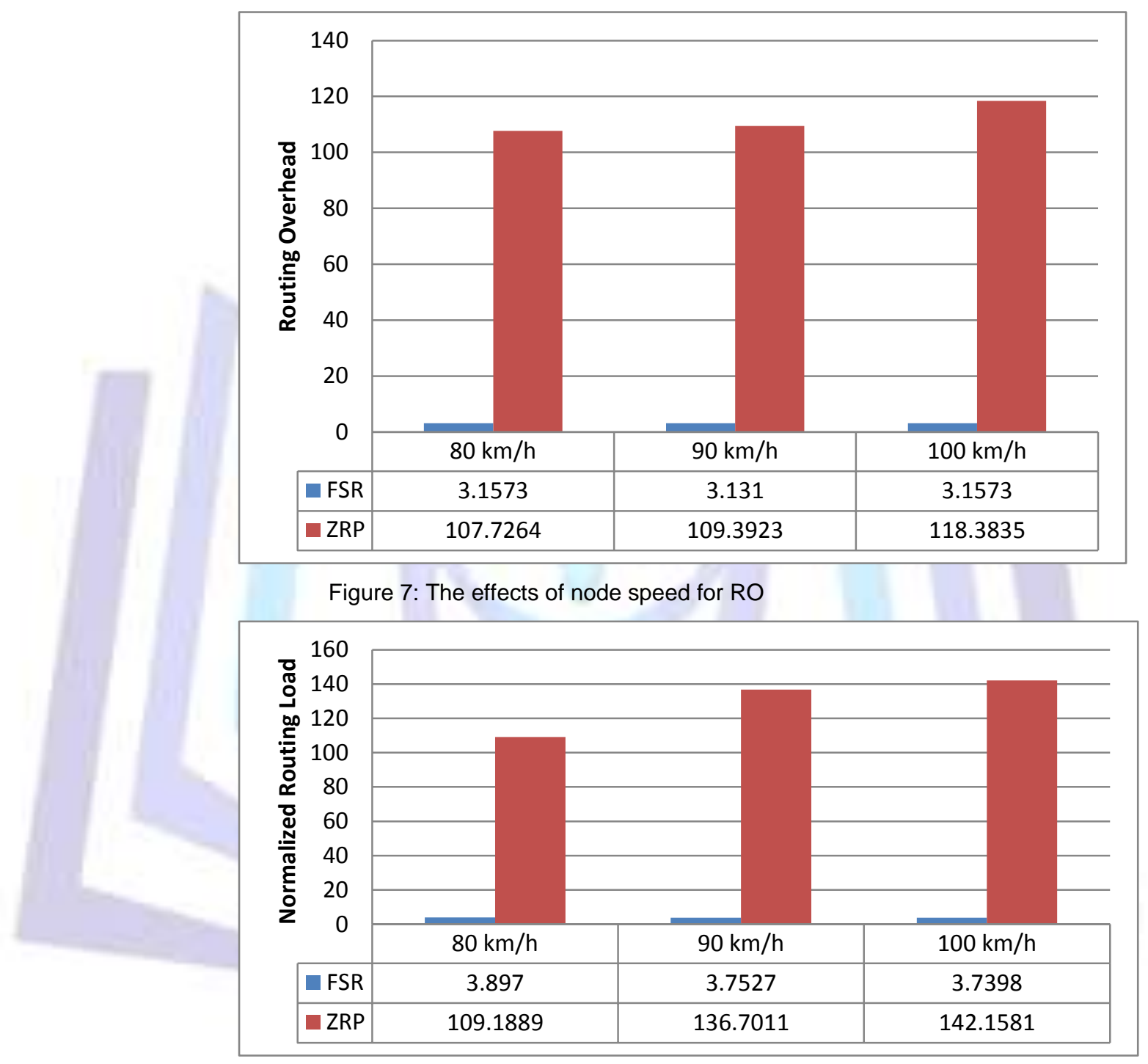

Figure 8: The effects of node speed for NRL

Routing Overhead is a comparison between the amounts of routing packet transmitted by routing protocol during the simulation divided by the amounts of sent packet by node source to node destination, this parameter showed the work efficiency of a routing protocol. It can be seen in Figure 7 that RO in ZRP way higher than the FSR in all scenarios. This was because ZRP always did the broadcast to all nodes located inside the zone to look for the node destination, if the node destination was unavailable in the zone, the peripheral node would again broadcast to the node inside the peripheral node. It caused the routing overhead value in ZRP was higher compared to FSR because it frequently did the broadcast so the routing packet value was higher and the routing overhead became bigger. In FSR, the proactive table routing protocol, it was based on link state protocol and had the ability to give routes information directly, if needed. The RO value would be small because FSR did not do the broadcast every time, but at particular period.

It can be seen that Normalized Routing Load in ZRP was higher than FSR. The value of NRL in ZRP tend to be increased as the node speed increased, this was because the faster the nodes move, the distant would be further so the zone in ZRP is needed in order to decrease the sending packet process. As a result, the Packet Delivery Ratio decreased and routing overhead increased so the NRL value became bigger. 


\section{c. Average End to End Delay}

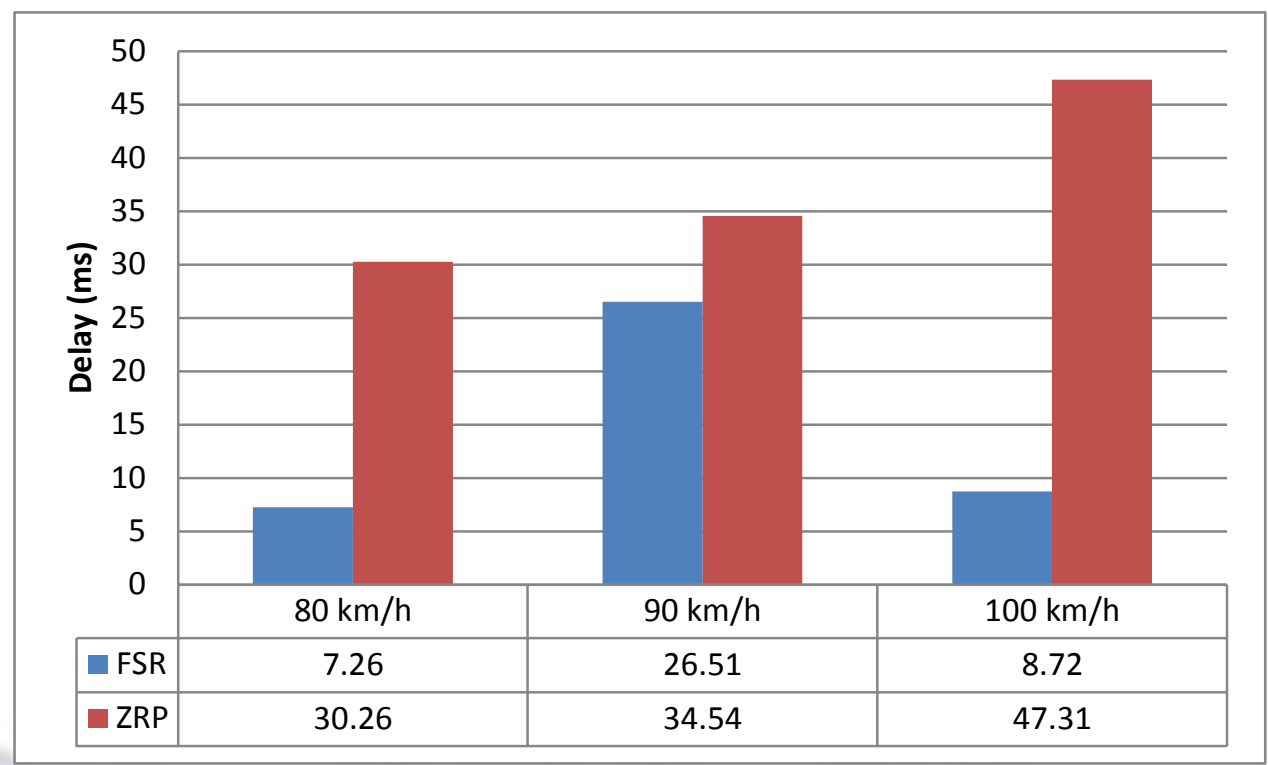

Figure 9: The effect of speed towards delay

End to end delay is the time used in a packet when it was being sent by a node and received in the node destination. The main factor that influences end to end delay was the time for routing protocol in finding route. It was because source node should know the route that connected to the destination. Another factor was delay process. When the node was receiving a message, the node would analyze the header to know to whom the packet given to then checked the destination of the packet.

FSR had better average of end-to-end delay which was $14.16 \mathrm{~ms}$, while ZRP was $37.37 \mathrm{~ms}$ because every node in FSR already has table routing information so when there a link disconnected, FSR did not need to re-search the route because there was route information in every node. In ZRP, if the link was disconnected in the IERP, the route research was needed, causing an abundant flooding and high delay.

\section{Node Amount Changes Scenario}

\section{a. Packet Delivery Ratio and Throughput Measurement}

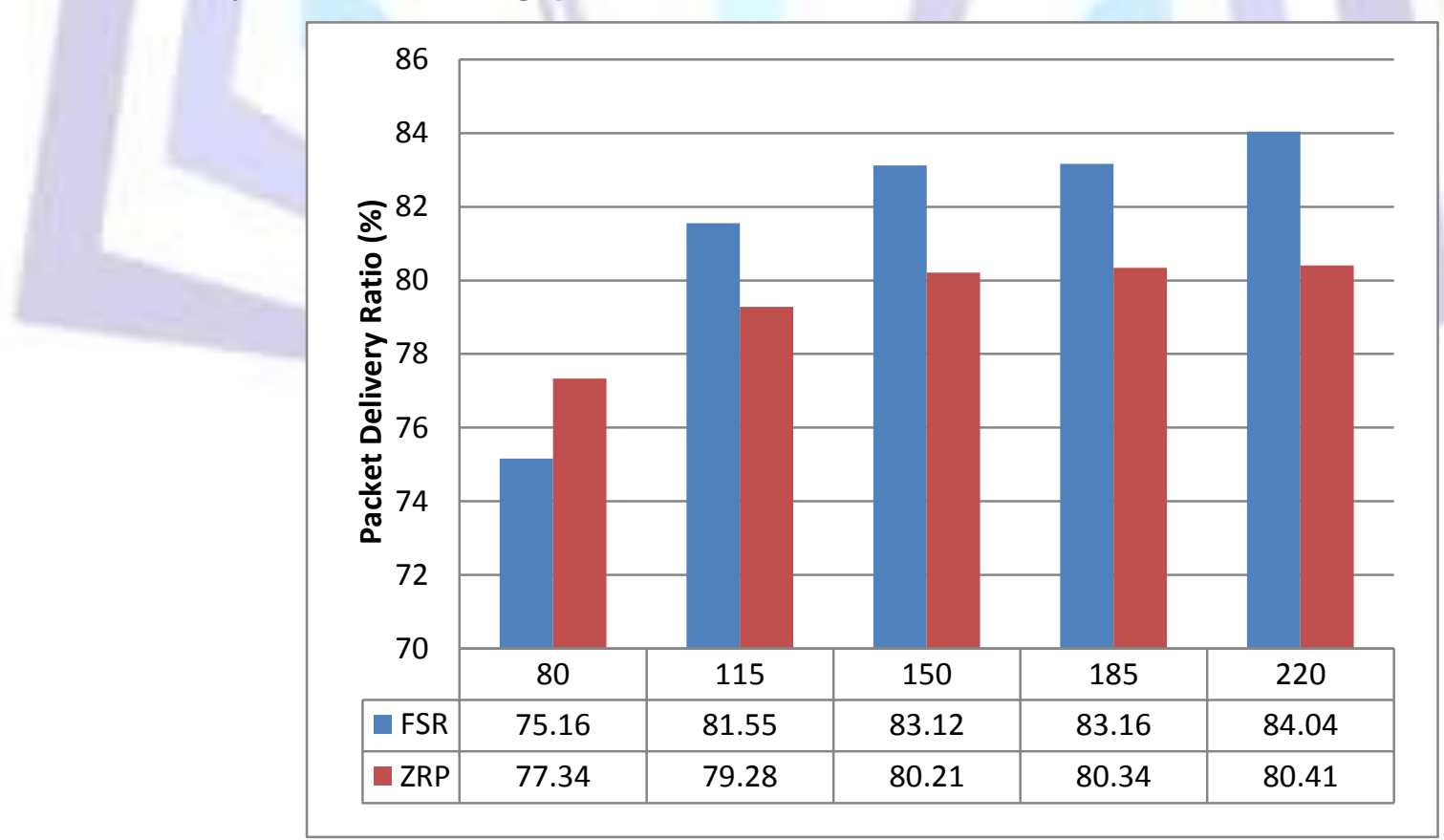

Figure 10: Effect of node amount towards PDR 


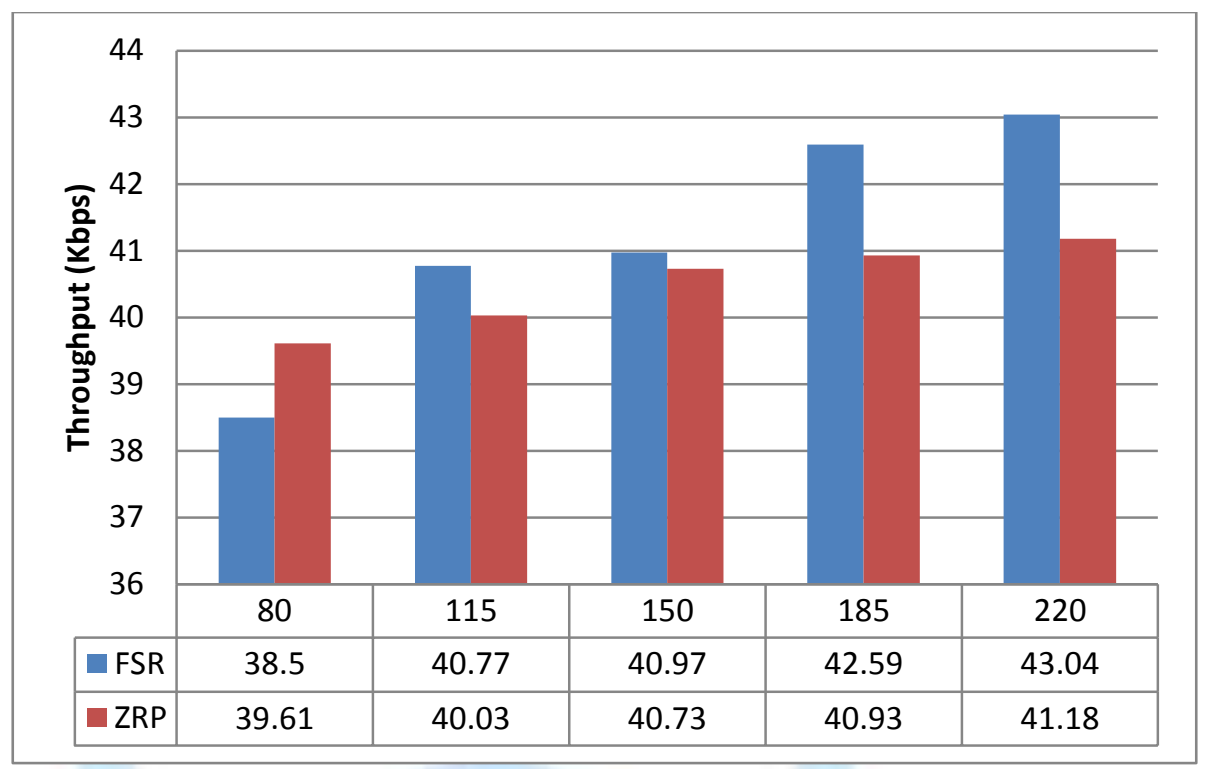

Figure 11: Effect of node towards throughput

Packet Delivery Ratio is a packet ratio which successfully received by node destination compared to the sent packet that sent by node source. The higher PDR means the better performance of the routing protocol was, it also showed better performance in assigning and seeking routes. Throughput is average speed of data received by the receiver. This parameter illustrated how much data could be sent through a network. Throughput measured in a measurement unit per time. The unit used was usually bit per second. Throughput value would be similar to PDR value because they illustrated the success of packet transfer. Throughput value influenced by some factors such as the consistency of network topology and the process of forming path. The more nodes in the network would decrease the link failure probability so the link endurance would be longer.

The graphic showed that both of protocols had increase trend when nodes were packed. FSR had higher PDR and throughput, $81.406 \%$ and $41.628 \mathrm{Kbps}$ while ZRP had $79.516 \%$ and $40.496 \mathrm{Kbps}$ in average. It showed that the crowds of nodes really influenced the succession of data transmission. In [8] mentioned that message range for safety warning application in VANET ranged from 50-300 m. If nodes were too few, the minimum distant could not be fulfilled so the PDR and throughput value were low.

The difference of PDR and throughput between FSR and ZRP was $18.9 \%$ and $1.132 \mathrm{Kbps}$ could be caused by the nodes in FSR had table routing for every node destination that could be reached by the network and did routing update anytime in particular period. The nearest node destination updated more often compared to the faraway node. FSR would always update its routing table even there was no communication request so the route discovery could be done at that time by using the table routing information. While in ZRP, link failure could possibly happen in IERP zone which used reactive routing protocol so it oblige the node to check the path that is going to use to the node source.

\section{b. Routing Overhead and Normalized Routing Load Measurement}

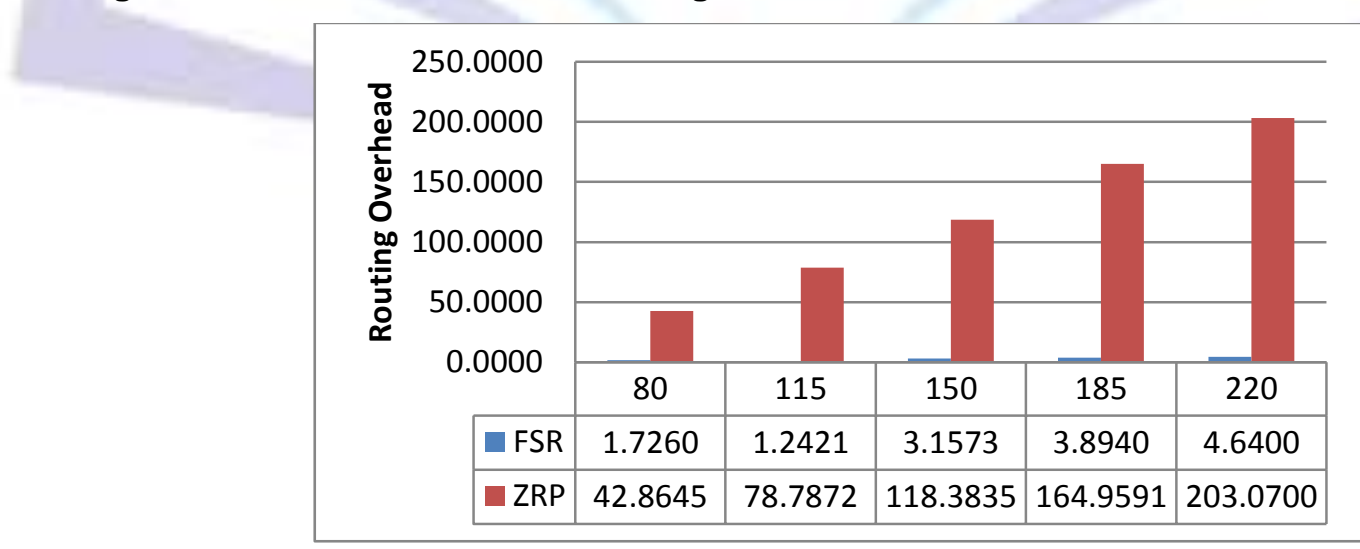

Figure 12: Effect of node amount towards RO 


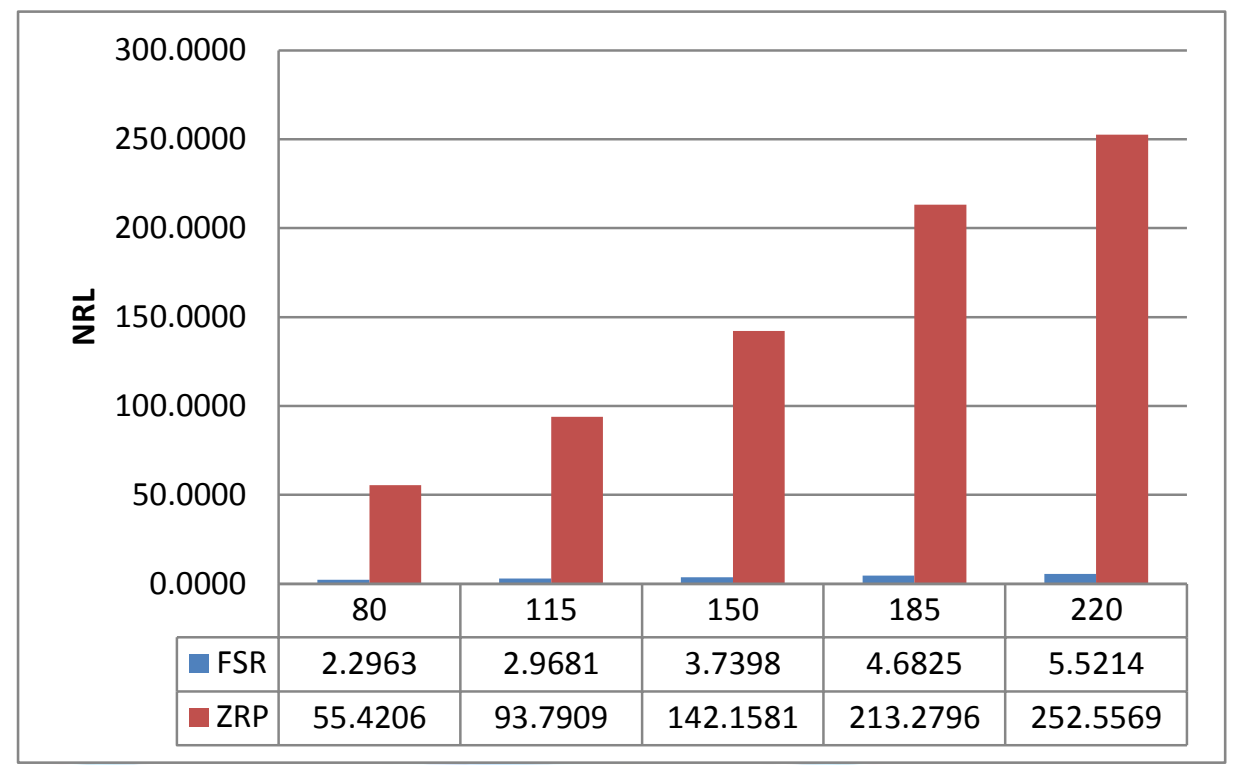

Figure 13: Effect of node amount towards NR

The value of Routing Overhead and Normalized Routing Load would be similar because this parameter was used to count the work efficiency of a routing protocol. $\mathrm{RO}$ is a comparison between the numbers of routing packet received with the packet sent, while NRL is a comparison between the numbers of packet sent with the packet received in the destination. The performance would be better if the RO and PDR value were low.

In the graphic, RO and NRL value influenced by the increase of node amounts, more nodes could cause the bigger burden of the protocol and the use of bandwidth channel would be bigger. RO and NRL value in ZRP were higher for every changes of node amount ranged from 42.86 to 203.07 and 55.42 to 252.55 . In FSR, RO and throughput ranged from 1.726 to 4.64 and 2.296 to 5.5214. FSR had low RO and NRL value because even it is a proactive routing protocol; it used fisheye system that updated routing table at certain period. FSR routing protocol used fisheye feature to broadcast the routing that renew information with different frequency and did not broadcast the update to the whole network so it decreased the routing overhead and NRL. In ZRP, the high RO and throughput value was because it is the protocol routing hybrid that used proactive protocol in IARP and reactive protocol in IERP. When the nodes were in IARP zone, the update routing table will be done continuously sot it gave more burden to the network causing high RO and throughput value.

\section{c. End to End Delay Measurement}

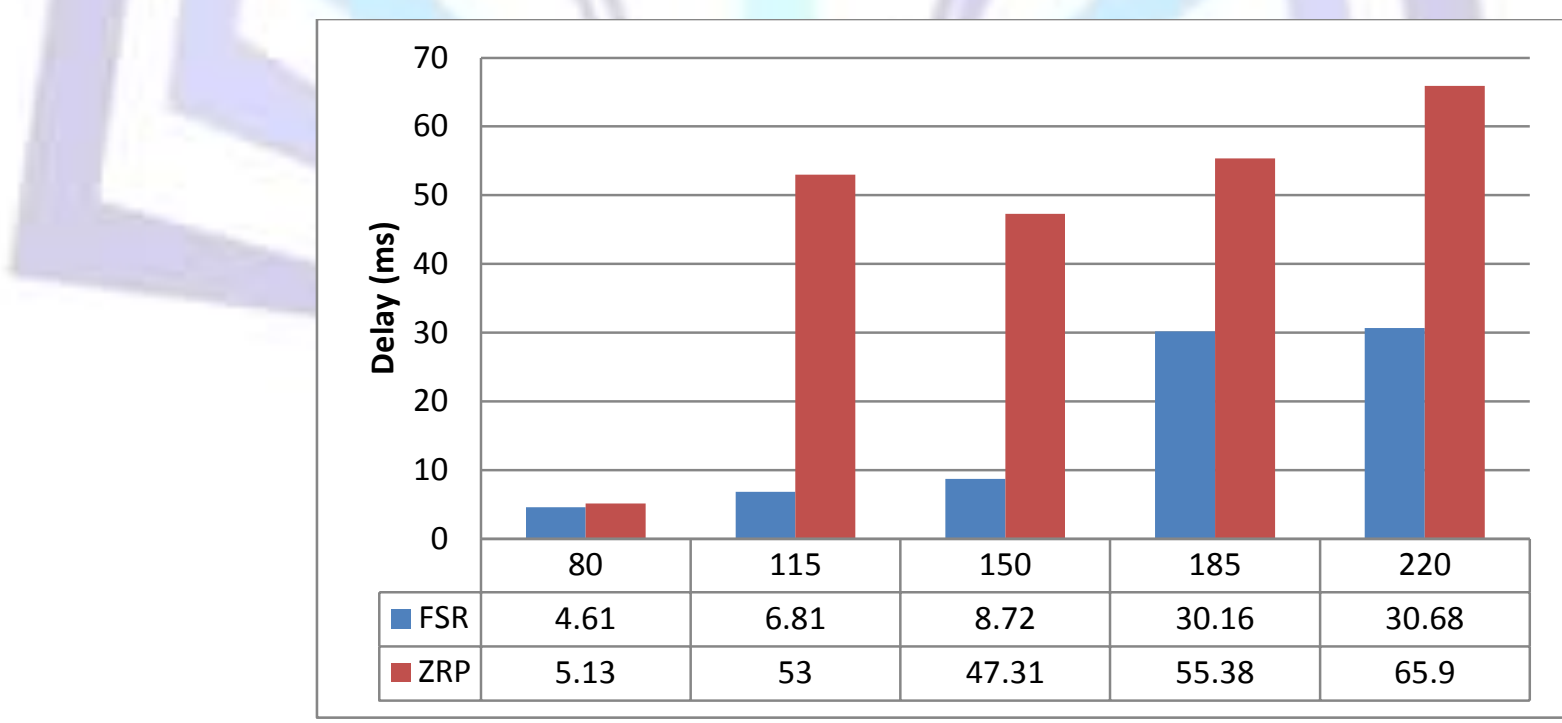

Figure 14: Effect of node amount towards delay

End to end delay is the time range went the packet was being sent until it arrived at the destination. Propagation delay, queue delay and route discovery process time were included in this delay. In the graphic, both of routing protocols had 
increase graphic trend, it was because the bigger amount of nodes will gave higher delay because the packet queue time and process increased. ZRP had higher delay value compared to FSR because ZRP needed to check whether the node destination located in IARP or IERP zone in advance. In FSR, every node already has routing table information so it could cut the time of data sending.

\section{Conclusion}

After the simulation and analysis were done towards the two algorithm routing protocol, it can be concluded that in the node speed changes scenario, FSR and ZRP showed decreased performances as the node speed increased. The faster nodes moved the further the distant would be, causing the higher link failure probability. But, FSR had shown better performance compared to ZRP as seen on the Routing Overhead parameter, NRL and Delay which were 3.1485, 3.7965, and $14.16 \mathrm{~ms}$ consecutively. In the implementation of VANET, delay was the main priority in assigning the routing protocol. The protocol with the lowest delay considered as the most appropriate one so the FSR routing protocol could be implemented in VANET well.

\section{REFERENCES}

[1] Anuj K. Gupta, Harsh Sadawarti and Anil K. Verma "Implementation Of DYMO Routing Protocol" International Journal of Information Technology, Modeling and Computing (IJTTMC) Vol.1, No.2, May 2013.

[2] Dhankhar, Shilpi,.ShilpyAgrawal. VANETs: A Survey on Routing Protocols and Issues. International Journal of Innovative Research in Science, Engineering and Technology. Vol. 3, Issue 6, June 2014

[3] Beijar, Nicklas. 2015. Zone Routing Protocol (ZRP). Networking Laboratory, Helsinki University of Technology Finlandia.

[4] J. Munera, J. M. de Fuentes, A. I. González-Tablas. Towards a comparable evaluation for VANET protocols: NS-2 experiments builder assistant and extensible test bed.

[5] Jaap, Sven,. Marc Bechler, Lars Wolf. Evaluation of Routing Protocols for Vehicular Ad Hoc Networks in Typical Road Traffic Scenarios.Institute of Operating Systems and Computer Networks.

[6] Kamini and Rakesh Kumar. "VANET Parameters and Application: A Review”. Global Journal of Computer Science and Technology, Volume 10, Issue 7, 2010.

[7] Karagiannis, G., Altintas, O., Ekici, E., Heijenk, G., Jarupan, B., Lin, K., and Weil, T., "Vehicular Networking: A Survey and Tutorial on Requirements, Architectures, Challenges, Standards and Solutions", IEEE Communications Surveys \& Tutorials, Vol.13, No.4, Fourth Quarter 2011.

[8] Khairnar, V. D. danKotecha, K.. 2013. Performance of Vehicle-to-Vehicle Communication using IEEE 802.11p in Vehicular Ad-hoc Network Environment. International Journal of Network Security and Its Applications, Vol.5, No.2, 143-170

[9] ntmckorlantaspolri.blogspot.com/2012/01/undang-undang-nomor-22-tahun-2009-pasal.html. Undang-UndangNomor 22 Tahun 2009, Pasal 287 ayat 5 Tentang Batas KecepatanKendaraan. diaksestanggal 14 September 2015

[10] Suthaputchakun, C., and Sun, Z., "Routing Protocol in Inter-vehicle Communication Systems: A Survey", IEEE Communications Magazine, December 2011.

[11] Singh, Abhishek. Simulation and Analysis of AODV, DSDV, ZRP in VANETs .2013. Computer Science And Engineering Department Thapar University 